\title{
A Olimpíada Nacional em História do Brasil (ONHB) como prática pedagógica no ensino médio integrado do IFRN
} The National Olympiad in History of Brazil (ONHB) as
pedagogic experience in technical high school at IFRN

Francisco das Chagas Silva Souza* José Gerardo Bastos da Costa Júnior**

\section{Resumo}

Neste artigo, discutimos acerca da participação de alunos do Ensino Médio Integrado (EMI) do Instituto Federal de Educação, Ciência e Tecnologia do Rio Grande do Norte (IFRN), Campus Mossoró, na Olimpíada Nacional em História do Brasil (ONHB), apresentada como alternativa pedagógica. Foram analisados cinco jornais, intitulados $\mathrm{Ga}$ zeta do Jovem Historiador, elaborados pelas equipes como cumprimento da $4^{\mathrm{a}}$ etapa da $3^{a}$ ONHB. Na oportunidade, os alunos realizaram pesquisas com história oral e entrevistaram sujeitos cujas profissões estão em extinção em virtude do desenvolvimento tecnológico. Também visitaram antigos lugares de trabalho que perderam a importância que ti-

\section{Abstract}

In this article, we aim at discussing an experience of participation of students from the Technical High School (THS) of the Federal Institute of Education, Science and Technology of Rio Grande do Norte (IFRN), Campus Mossoro, in the National Olympiad in History of Brazil (NOHB). The methodology consisted of five newspapers analysis, entitled Gazeta do Jovem Historiador, prepared by the teams as the fulfillment of the 4 th stage of the $3 \mathrm{rd} \mathrm{NOHB}$. On the occasion, the students conducted research on Oral History and interviewed subjects whose jobs are endangered due to technological development. They also visited former workspaces that have lost the importance they had a few decades

\footnotetext{
* Doutor em Educação pela Universidade Federal do Rio Grande do Norte (UFRN). Professor do Instituto Federal de Educação, Ciência e Tecnologia do Rio Grande do Norte (IFRN), Campus Mossoró. Professor do Programa de Pós-Graduação em Ensino (IFRN/Ufersa/UERN) e do Programa de Pós-Graduação em Educação Profissional (IFRN). Mossoró, RN, Brasil. chagas. souza@ifrn.edu.br

** Licenciado em História. Mestrando do Programa de Pós-Graduação em Ensino (IFRN/Ufersa/ UERN). Professor de História do Instituto Federal de Educação, Ciência e Tecnologia do Rio Grande do Norte (IFRN), Campus Mossoró. Mossoró, RN, Brasil. gerardo.junior@ifrn.edu.br
} 
veram há algumas décadas. A ONHB propiciou, para o ensino de História no EMI, possibilidades de trabalhos interdisciplinares e de reflexão sobre as mudanças no mundo do trabalho.

Palavras-chave: Olimpíadas do conhecimento; Ensino de História; Ensino Médio Integrado. ago. The NOHB provided for the teaching of history at THS, possibilities of interdisciplinarity and the approach of issues related to the changings in the world of work.

Keywords: Olympics of knowledge; History Teaching; Technical High School.

As chamadas olimpíadas do conhecimento vêm ganhando espaço na educação brasileira durante as últimas décadas. Elas são muitas (algumas têm alcance internacional) e envolvem um grande número de disciplinas e áreas científicas: Astronomia, Agropecuária, Biologia, Física, Informática, Geografia, Linguística, Matemática, Química, Robótica, Saúde e Meio Ambiente, Língua Portuguesa, Oceanografia, História do Brasil, dentre outras. Os alunos medalhistas mais bem classificados têm a chance de participar de programa de Iniciação Científica Júnior com bolsas do Conselho Nacional de Desenvolvimento Científico e Tecnológico (CNPq). Como destaca o jornalista Ênio Rodrigo (2013): "O desafio proposto por essas competições motiva discentes, professores e escolas, sem contar as famílias dos estudantes. Esses eventos se tornaram um celeiro de futuros grandes pesquisadores".

Neste artigo, tencionamos discutir a participação de estudantes do Ensino Médio Integrado (EMI) do Campus Mossoró do Instituto Federal de Educação, Ciência e Tecnologia do Rio Grande do Norte (IFRN) na Olimpíada Nacional em História do Brasil (ONHB), considerando seu potencial para o processo de ensino-aprendizagem de História.

Diante da vastidão de material de que dispomos a respeito das provas da ONHB, resolvemos usar, como recorte, a elaboração de jornais realizada pelas equipes na $4^{\mathrm{a}}$ fase da $3^{\mathrm{a}}$ Olimpíada. Esses jornais foram intitulados Gazeta do Jovem Historiador. Na oportunidade, os alunos realizaram pesquisas com história oral e entrevistaram trabalhadores cujas profissões estão em declínio em face do desenvolvimento tecnológico. Também visitaram antigos lugares de trabalho que perderam a importância que tiveram há décadas.

Motivou a seleção dessa experiência na $3^{a} \mathrm{ONHB}$ o fato de ela vir ao encontro da proposta dos professores de História do IFRN em trabalhar na 
perspectiva da chamada História Temática, consoante o documento "Projeto de Trabalho da Disciplina do Ensino Médio - História” (Instituto..., 2012).

Este artigo está dividido em três partes. Na primeira, apresentamos alguns elementos que caracterizam a ONHB do ponto de vista pedagógico. Em segui$\mathrm{da}$, discorremos a respeito de uma pesquisa de campo desenvolvida por cinco equipes do IFRN/Mossoró durante a realização de uma tarefa da $4^{\mathrm{a}}$ fase da $3^{\mathrm{a}}$ ONHB. Por fim, como considerações finais, discutimos a importância dessa tarefa para a formação acadêmica e profissional dos estudantes e sua contribuição para o ensino de História na Educação Profissional.

\section{A Olimpíada Nacional em História do Brasil}

A ONHB teve inicio em 2009 e era desenvolvida, a princípio, pelo Museu Exploratório de Ciências da Unicamp. A partir de 2013, passou a ser realizada pelo Departamento de História dessa universidade. Conforme encontramos no sítio da ONHB, ${ }^{1}$ o evento é uma iniciativa inovadora para estimular o estudo e o debate da história nacional, por meio da leitura e da interpretação de documentos, imagens e textos.

As equipes participantes da ONHB são compostas por três estudantes e orientadas por um professor de História. Podem participar delas estudantes de instituições públicas ou privadas de qualquer parte do país, regularmente matriculados nos oitavo e nono anos do Ensino Fundamental ou no Ensino Médio.

A ONBH é dividida em seis fases. As cinco primeiras se dão com provas on line; a sexta fase ocorre presencialmente, na Unicamp, quando as equipes que obtiveram maior pontuação nas etapas anteriores respondem a uma prova escrita, organizada por questões dissertativas e argumentativas. Após a avaliação dessa prova, realizada pela equipe da Unicamp, e a soma dos pontos, ocorre a premiação com a entrega de quinze medalhas de ouro, 25 de prata e 35 de bronze.

Na cerimônia de abertura da $4^{\text {a }}$ ONHB, em 2012, Marcelo Firer, ex-diretor do Museu Exploratório de Ciências da Unicamp, afirmou que os participantes dedicam, em média, quinze horas por semana para a resolução das fases on-line. Para ele, "essa dedicação é fruto de uma prova de altíssima qualidade, que representa um verdadeiro desafio intelectual ao mesmo tempo que é 
bonita, charmosa e instigante". Ainda de acordo com Firer, na referida solenidade, muito mais que uma competição, a ONHB é um processo de aprendizagem, que não foca apenas no que os estudantes sabem sobre História, mas naquilo que eles são capazes de aprender ao longo das fases da Olimpíada.

As etapas da ONHB são distribuídas ao longo de quatro meses, quando se desenvolve um trabalho de preparação dos discentes por parte dos professores. Eles acompanham os alunos no acesso às provas e orientam-nos a seu respeito. Geralmente, tudo aquilo que as equipes necessitam para a resolução das questões está disponível no sítio da Olimpíada na Unicamp. Conforme salienta a professora Cristina Meneguello, pesquisadora do Instituto de Filosofia de Ciências Humanas (IFCH) da Unicamp e coordenadora da ONHB (2011, p.5):

foram desenvolvidos uma plataforma e um sistema interativos que, além de proporcionar a inclusão digital, possibilitaram atividades, como a utilização de um acervo digitalizado de documentos históricos, o que leva os participantes a terem contato direto com o arcabouço metodológico do historiador. Atividades como leitura e interpretação de documentos, análise de materiais iconográficos (mapas, gravuras, mídia em geral) e a interpretação de documentos controversos sobre o mesmo evento histórico foram algumas das atividades propostas às equipes. Todo o material está disponível on line ... e o acesso às perguntas dos concursos passados é constante, seja para estudos, seja para utilização de imagens e textos por parte dos docentes, dentro da área que chamamos de "repositório de documentos".

Em entrevista concedida à imprensa, Meneguello observa que, apesar de não haver uma relação direta das olimpíadas científicas com indicadores de avaliação, como o Índice de Desenvolvimento da Educação Básica (Ideb) e o Programa Internacional de Avaliação de Estudantes (Programme for International Student Assessment - Pisa), há um aumento do nível de estudo em geral nas instituições que se dedicam a esses eventos (Rodrigo, 2012).

Nas quatro primeiras fases, as questões da ONHB são de múltipla escolha, com diferentes níveis de acerto e de pontuação. Além de uma tarefa que, na $4^{\mathrm{a}}$ fase, envolve uma pesquisa de campo (levantamento de dados, entrevistas, busca por fontes históricas, dentre outras atividades). 
$\mathrm{Na} 3^{\mathrm{a}} \mathrm{ONHB}$, objeto de nosso estudo, os elaboradores das questões da $4^{\mathrm{a}}$ fase propuseram a organização de um jornal virtual intitulado Gazeta do Jovem Historiador. Importa destacar, a título de informação, que as tarefas da $4^{\mathrm{a}}$ fase são avaliadas na etapa seguinte pelos estudantes que continuam na competição. Nesse momento, a capacidade dissertativa das equipes (produção e análise de texto) é avaliada por outras equipes concorrentes, mas também, nessa ocasião, ocorre uma autoavaliação entre seus membros, visto que discutem os trabalhos que estão avaliando e comparam-nos aos seus. Ou seja, nessa fase, desenvolve-se uma habilidade importante, mas muitas vezes negligenciada no cotidiano escolar: a possibilidade de o aluno se examinar e refletir sobre o seu crescimento cognitivo.

Ao estudarem juntos os diferentes materiais oferecidos pela organização da ONHB, geralmente de proposição interdisciplinar (documentos históricos, textos acadêmicos e literários, charges, pinturas, dentre outros), professores e alunos terminam por questionar algumas versões de fatos históricos encontradas nos livros didáticos dessa disciplina. Isso traz, para os envolvidos no evento, a descoberta do novo em termos de pesquisas acadêmicas, fontes históricas e interpretações dos fatos. Dessa maneira, fica claro para todos que o conhecimento está sempre em processo de construção e que devemos buscá-lo, respeitando os seus diversos aspectos e dimensões, característica importante na formação de um cidadão crítico (Mello, 2011).

Ao inserir textos literários, propor análises de charges, cartografias, gráficos e tabelas, elaboração de jornal virtual e entrevistas, a ONHB estimula a criatividade dos participantes e exercita práticas interdisciplinares. Como observa Bittencourt (2011, p.106),

Em História, não se entende como apreensão de conteúdo apenas a capacidade dos alunos de dominar informações e conceitos de determinado período histórico, mas também a capacidade das crianças e jovens de fazer comparações com outras épocas, usando, por exemplo, dados resultantes da habilidade de leitura de tabelas, gráficos e mapas ou de interpretação de textos.

Na sociedade atual, em que uma vastidão de informações e de tecnologias a todo instante veicula novas e diferentes versões sobre acontecimentos do cotidiano, a ONHB age no sentido de proporcionar alternativas de métodos de ensino de História no Brasil (e do Brasil). Nesse aspecto, ela segue em 
direção a um dos pressupostos apresentados por Bittencourt (2011, p.107): “os atuais métodos de ensino têm de se articular às novas tecnologias para que a escola possa se identificar com as novas gerações, pertencentes à 'cultura das mídias"”.

Feitas essas considerações iniciais sobre a ONHB, abordamos, a seguir, o trabalho de pesquisa desenvolvida por cinco equipes, ou seja, quinze alunos de cursos técnicos do IFRN, Campus Mossoró, durante a realização de uma atividade desse evento.

\section{A Gazeta do Jovem Historiador}

Conforme destacado anteriormente, além de responder a questões de múltipla escolha, uma tarefa da $4^{\mathrm{a}}$ fase da $3^{\mathrm{a}} \mathrm{ONHB}$ consistia na elaboração da Gazeta do Jovem Historiador, cuja temática eram as transformações no mundo do trabalho, um tema recorrente nessa edição da Olimpíada. ${ }^{2}$ Assim, abordando o desaparecimento - ou crise - de profissões e ofícios, bem como as transformações nos locais onde essas atividades eram desenvolvidas, os alunos deveriam elaborar reportagens temáticas, as quais resultariam de três exercícios práticos, conforme orientações a seguir:

\section{Entrevista}

Como primeiro passo da tarefa, os participantes deverão identificar quais pessoas desejam entrevistar (fontes), tomando o cuidado para que essas pessoas estejam relacionadas ao tema proposto. Ou seja, devem ser pessoas que possam contribuir com informações relativas a profissões ou ofícios que exerciam e que demandavam saberes específicos, tais como sapateiros, ferreiros, seleiros, doceiras, lavadeiras, engraxates, barbeiros, caixeiros-viajantes, entre outros. Após escolhida a fonte para entrevista, a ONHB sugere algumas perguntas que poderão ser feitas ao entrevistado, mas os membros das equipes têm liberdade para elaborar quantas perguntas desejarem.

\section{Fotografia}

O segundo passo da tarefa consiste em fotografar um local de trabalho. No entanto, o local não deve ser um espaço de trabalho fundado recentemente, já que a tarefa tem como tema geral a memória do trabalho. O prédio pode estar abandonado, fechado ou ainda estar em pleno funcionamento. A foto poderá ser da 
fachada ou do interior, revelar pessoas e maquinário, ou apenas o edifício. Uma vez feita a imagem, os participantes deverão atentar para uma série de informações acerca da construção, como ano de fundação, número de funcionários, ramo de atividade, entre outros dados solicitados pela ONHB.

\section{Produção de texto}

Diante dos dados coletados nas etapas 1 e 2 da tarefa, os participantes estarão prontos para produzir os textos que farão parte da Gazeta do Jovem Historiador. A linguagem utilizada deverá ser a jornalística, sendo precisa, sintética e de rápida comunicação.

Em seguida a essas orientações, foi apresentado um modelo que as equipes seguiriam na confecção do jornal (Figura 1).

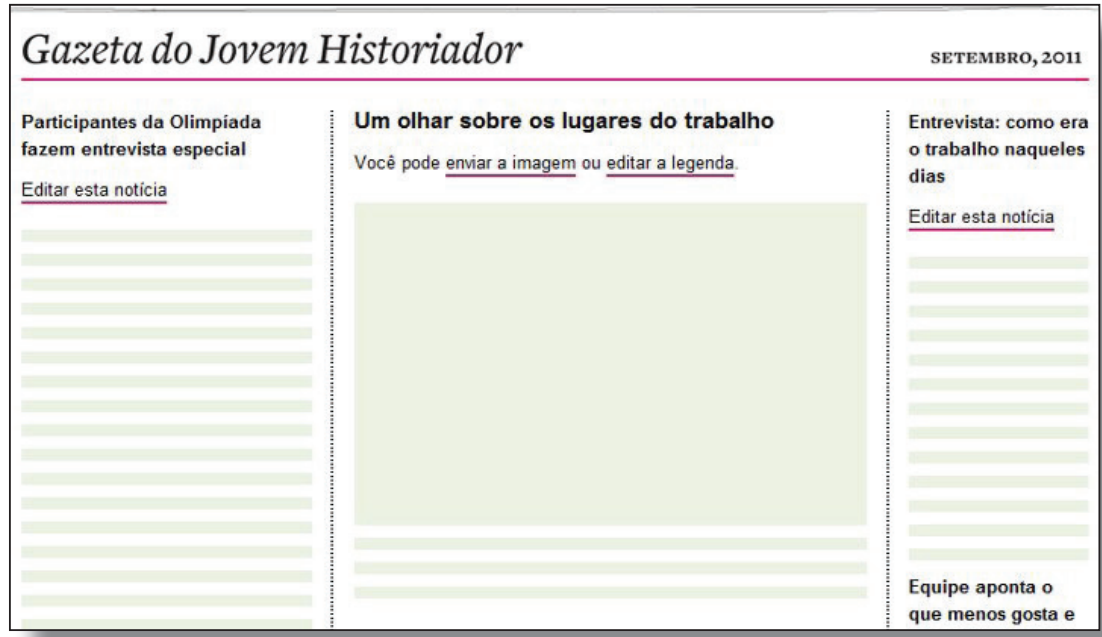

Figura 1 - Modelo proposto para a elaboração da Gazeta do Jovem Historiador

Sete equipes $^{3}$ (ou seja, 21 alunos) do IFRN, Campus Mossoró, executaram a tarefa acima destacada. Esses alunos pertenciam aos cursos técnicos de Informática, Eletrotécnica e Edificações, nos turnos matutino e vespertino, e foram orientados por três professores de História.

De acordo com as instruções da Comissão Organizadora da ONHB, antes de procederem às entrevistas, os estudantes solicitaram aos possíveis entrevistados, por meio de uma carta-convite, a concessão da entrevista e a autorização 
para sua divulgação no sítio da Olimpíada. De posse desse consentimento, foram marcados a hora e o local para a realização dos depoimentos. Algumas equipes usaram gravadores, enquanto outras registraram as narrativas por escrito, em um caderno.

Entre os trabalhadores cujas profissões estão hoje em declínio, foram entrevistados dois ex-ferroviários, uma bordadeira e costureira, um alfaiate e um confeccionador de placas para automóveis. Por uma questão ética, optamos por não apresentar aqui seus nomes.

As Equipes 1 e 2 entrevistaram dois ferroviários aposentados, uma profissão que, em Mossoró-RN, é praticamente extinta, visto não haver mais fluxo na antiga estação de trem, que hoje é um espaço destinado a atividades culturais, como trataremos adiante.

O ex-ferroviário entrevistado pela Equipe 1 é paraibano, mas reside em Mossoró-RN há várias décadas. Na antiga Estação Ferroviária de Mossoró, ele exerceu tarefas como: ligações telefônicas, escrituração da agência, despacho das mercadorias e licenciamento, além de operação do telégrafo por meio de código Morse. Sua jornada de trabalho se iniciava às 6 horas da manhã e só tinha fim quando encerrava o fluxo dos trens, o que poderia ocorrer somente à noite. Apesar da sobrecarga, ele afirmou serem boas as suas condições de trabalho. Posteriormente, o ex-ferroviário passou a trabalhar no Sindicato da Rede Ferroviária, que, à época, possuía cerca de trezentos associados, número que decaía à medida que esses trabalhadores se aposentavam e esse tipo de transporte perdia sua importância no Brasil, particularmente em Mossoró. Com saudade, o ex-ferroviário destaca: “já sonhei várias vezes que estava trabalhando na estação de trem".

A Equipe 2 entrevistou um ferroviário aposentado da cidade de Caraúbas-RN, o qual, ao contrário de seu colega de trabalho de Mossoró, contatado pela Equipe 1, relatou as dificuldades que viveu naquela profissão. Segundo ele, mesmo que recebessem os direitos trabalhistas, as condições de trabalho não eram tão boas e os acidentes eram comuns, já que tudo era feito manualmente e não existiam equipamentos de proteção. Ao 76 anos, à época da entrevista, ele confessa não sentir saudades do trabalho, visto que era muito árduo. Entretanto, orgulha-se dele, pois, conforme seu relato, foi trabalhando ali que conseguiu criar seus filhos e netos: "Foi uma batalha que consegui vencer", disse. 
A Equipe 3 entrevistou uma bordadeira que, à época, possuía 76 anos de idade e residia em Mossoró-RN. Demonstrando muita saudade de seu trabalho, ela afirmou que começou a bordar e a costurar aos quinze anos, com a ajuda de uma amiga, no município de Cerro Corá-RN. Juntas, “fazíamos de tudo: vestes simples, roupas para festas, vestidos de noiva. Em tempos de festa, a demanda por nosso trabalho era grande. Bordávamos dia e noite. Era cansativo, mas bom. Ganhávamos nosso próprio dinheiro", disse. Ressaltou que, naquela época, seu ofício era mais valorizado: “Tínhamos muito o que fazer. Havia tempos em que trabalhávamos todos os dias, sem parar”. A bordadeira relatou, com tristeza, que, com o desenvolvimento da indústria e a modernização da tecnologia, o bordado perdeu muito valor. Um ofício que, antes manual, tornou-se cada vez mais automatizado: "Fomos substituídas por máquinas ... As pessoas nada sabem de nossa história, de como passávamos conhecimento de geração em geração. Hoje não há tempo para isso”.

A Equipe 4 entrevistou um alfaiate, à época com 72 anos, natural de Caraúbas-RN, mas residente em Mossoró/RN desde os cinco anos de idade. Ele contou que, aos dezesseis anos, aprendeu o ofício com o pai, com quem passou a trabalhar. Narrou à equipe que, ao contrário da maioria das alfaiatarias de Mossoró, que atendiam à elite, seu pai produzia roupas mais acessíveis financeiramente para os trabalhadores mossoroenses. O alfaiate explicou que, como trabalhava em casa, a rotina "começava quando tinha trabalho e acabava quando terminava as encomendas". Portanto, não tinha hora certa para começar ou acabar o expediente. Com o falecimento do pai, ele deu continuidade ao seu trabalho, mas infelizmente a procura por alfaiates entrou em decadência devido à produção de roupas em série, nas fábricas, mais baratas se comparadas às confeccionadas manualmente. Assim, a alfaiataria parou de funcionar, mas o seu antigo alfaiate diz sentir "saudade e orgulho, porque eu sempre era elogiado quando fazia uma roupa. O trabalho valia a pena”.

A Equipe 5 entrevistou um antigo confeccionador de placas para automóveis, um conhecido poeta popular em Mossoró-RN, que também já foi sapateiro e xilógrafo, profissões que atualmente são consideradas atrasadas. Porém, o poeta e plaqueiro se defendeu: "atraso é ter alguém fazendo uma placa à mão? Atraso é uma sociedade onde tem gente pedindo esmola”. Demonstrou ainda a sua indignação quanto ao descaso do sistema capitalista com as profissões artesanais: "Em todos os períodos históricos, sempre houve espaço para o 
artesão ... Eu sinto muito a tecnologia passar por cima dessas profissões sem dó nem piedade".

À equipe, ele contou que trabalhava em uma oficina, com três companheiros. A rotina de trabalho era dura, de quase doze horas diárias. Apesar disso, tem orgulho em dizer que "achava muito bom pegar o ferro, manusear a placa ... Além de a pessoa estar precisando, eu fazia uma coisa bonita". Tendo aprendido esse ofício para ajudar no sustento da família, posteriormente, continuou a produzir placas por gostar da arte e repassou seus conhecimentos para outras pessoas. Essas placas, relatou, eram vendidas a clientes de diversos lugares do Brasil. Com saudade, ele considerou que foi feliz enquanto trabalhava com as placas e que se sentia muito entristecido pelo fato de a mão do artesão ser avassaladoramente substituída por máquinas de alta tecnologia.

No que diz respeito aos lugares do trabalho, a Equipe 1 pesquisou e visitou a antiga Estação Ferroviária Mossoró-Sousa, hoje, Estação das Artes Elizeu Ventania. O projeto da estação ferroviária teve início em 1875, quando a cidade era um polo comercial na região, por iniciativa de Ulrich Graf, industrial suíço radicado em Mossoró. Ele planejava a construção de uma estrada de ferro para o transporte de sal, gesso e minérios, mas isso só se tornou realidade em 31 de agosto de 1912, quando a firma Sabóia \& Cia deu início aos trabalhos da Companhia Estrada de Ferro de Mossoró S/A. Dois anos e meio depois, foi inaugurado o primeiro trecho, entre Porto Franco e Mossoró, em 1915.

Até 1951, quando foi inaugurada a Estação Ferroviária de Sousa-PB, a Companhia, que se chamava Estrada de Ferro Mossoró, passou a ser chamada Estrada de Ferro Mossoró-Sousa. O percurso da ferrovia também aumentou e o comércio se intensificou, com o incremento do volume de produtos vindos de Campina Grande, na Paraíba, para Mossoró. Além de abastecer a região, os trens cargueiros também traziam o açúcar e o cimento do estado do Pernambuco, aquecendo as relações interestaduais. Não se sabe ao certo quantas pessoas trabalharam na antiga Estação Ferroviária de Mossoró, que funcionou por mais de oitenta anos. Entre os cargos exercidos pelos ferroviários, estavam: agentes de estação, guarda-freios, chefes, maquinistas, feitores e foguistas.

Com a conclusão da Rodovia RN-117, no início da década de 1980, por outro lado, aumentou o fluxo de veículos, tanto de pequeno quanto de grande portes, além dos ônibus que também faziam linhas pelas cidades do interior. Como a viagem de ônibus era mais rápida e confortável, ela passou a ter a 
preferência da população, mesmo sendo as passagens de trem mais baratas. A crise foi se agravando com o passar do tempo, até os prejuízos obrigarem os diretores da velha ferrovia a desativarem definitivamente os trens de passageiros. O fato se concretizou no dia 30 de janeiro de 1988, quando partiu de Mossoró o último trem de passageiros com destino a Sousa-PB. Mais tarde, em 1995, os trens cargueiros também foram desativados.

A antiga Estação Ferroviária, depois de vários anos abandonada, foi restaurada, pintada com cores diferentes da original e, atualmente, nomeia-se Estação das Artes Elizeu Ventania, palco de festividades de Mossoró. Nela também se concentram um museu e um miniteatro. Seus trilhos foram arrancados, suas oficinas estão em ruínas, como também estão os armazéns à sua volta. Assim, as locomotivas, que antes cortavam a cidade, desapareceram.

A Equipe 2 escolheu pesquisar a respeito da Estação Ferroviária de Caraúbas-RN. Fundada em 30 de setembro de 1929, essa estação foi criada com o intuito de servir como ponta da linha Porto Franco-Caraúbas. Naquela época, o ritmo da cidade girava em torno dessa linha ferroviária. O trem era o principal meio de transporte da população para viagens mais longas e transportava cargas e animais, sendo, por isso, importante para o setor terciário do município. A estação também servia como intermédio para a cidade de São Sebastião (hoje denominada Governador Dix-sept Rosado), viabilizando o transporte da gipsita, cujas jazidas, no interior do Rio Grande do Norte, estavam entre as maiores do Brasil.

Como ocorreu em outras pequenas cidades brasileiras, em Caraúbas, o advento de novos meios de transporte (ônibus, carros e motocicletas) tornou o trem um transporte em desuso, ocasionando a desativação da linha ferroviária em 1980. Esse fato causou grande impacto na vida dos caraubenses, que se mostraram insatisfeitos com essa decisão, pois muitos haviam abandonado o trabalho na agricultura e migrado para a cidade a fim de trabalhar na Estação Ferroviária, considerada mais atrativa, pois os ferroviários possuíam um salário mensal e direitos trabalhistas que outras profissões não concediam na época.

Depois de quase três décadas desativada e abandonada, em dezembro de 2007, a antiga Estação Ferroviária de Caraúbas foi transformada na Casa de Cultura Popular "Manoel do Violão" e tombada como patrimônio da cidade. Como ocorreu em Mossoró, hoje, suas instalações abrigam um museu e, no 
seu entorno, ocorrem manifestações culturais da cidade (festas, grupos de teatro, dança, violeiros, artesanato).

A outrora imponente fábrica de sucos Maisa, localizada nos arredores de Mossoró-RN, foi o local de trabalho escolhido para a pesquisa da Equipe 3. A partir da década de 1970, importantes empresas nacionais e grupos internacionais assumiram o ramo da fruticultura irrigada em Mossoró e região. Um dos pioneiros foi o Grupo Agroindustrial Maisa, fundado no município de Mossoró pelos engenheiros Geraldo Cabral e José de Sá. À época, essa empresa contava com mais de seis mil funcionários diretos. Na década seguinte, alcançou seu auge, atingindo quase sete mil empregados.

A Maisa possuía o melão como cultura principal, destinada à exportação, mas também cultivava caju, abacaxi, tamarindo e maçã. A empresa conquistou boa reputação em âmbito nacional e internacional e contribuiu efetivamente para o crescimento da economia norte-riograndense. Com o desenvolvimento da fábrica, aos poucos, um pequeno povoamento foi se formando ao seu redor. Havia casas para operários, creches, escolas, posto médico e mercado. O número de trabalhadores cresceu tanto que o espaço se transformou numa vila.

Ao visitar as antigas instalações da Maisa, a Equipe 3 conversou com um ex-operário que começou a trabalhar nessa empresa com quinze anos de idade. Indagado sobre o período, afirmou: "No começo, chorei muito. Não estava acostumado ao trabalho em fábricas. A quantidade de horas, o trabalho pesado... tudo era novo e chocante para mim. Depois, comecei a gostar do lugar. Produzíamos muito e ajudávamos nossa cidade a crescer. Havia grande amizade entre os trabalhadores. Éramos respeitados pela população".

A Equipe 3 visitou o conjunto da Maísa com o objetivo de conhecer suas condições físicas após cerca de quarenta anos de funcionamento. A impressão foi de abandono e degradação, com prédios desativados, destruídos e máquinas obsoletas. A implantação do Plano Real durante o governo de Itamar Franco mergulhou a empresa numa grande crise. A indústria chegou a decretar falência em 2003. Na época da pesquisa para a ONHB, a Maisa havia sido parcialmente reativada e tinha apenas 35 funcionários.

A Equipe 4, quando da entrevista com o alfaiate, visitou sua residência, onde funcionava sua alfaiataria, fundada por volta de 1935, por seu pai. Essa alfaiataria, pela sua simplicidade, passa despercebida como patrimônio histórico e não demonstra a importância que já teve para a cidade. Nela, trabalharam dois alfaiates, 
pai e filho, que, como já afirmamos anteriormente, costuravam roupas mais simples para atender às pessoas de menor poder aquisitivo da sociedade mossoroense. Com o declínio da alfaiataria, em função das roupas, mais baratas, produzidas pelas fábricas, a casa dos alfaiates hoje assemelha-se a uma casa abandonada.

A oficina de placas para automóveis, em atividade desde 1974 na própria residência de um poeta popular muito conhecido em Mossoró, foi o objeto da pesquisa da Equipe 5. Quando foi criada, a oficina era completamente artesanal, ou seja, cada letra das placas era feita manualmente. Com o tempo, no entanto, seu proprietário construiu uma máquina para auxiliá-lo na confecção. Apesar da concorrência com as grandes empresas associadas ao Departamento de Trânsito, a oficina foi de grande importância para a cidade de Mossoró. Nela eram fabricadas as mais variadas placas para automóveis, de acordo com a necessidade do cliente.

\section{Algumas CONSIDERAÇões}

A realização da tarefa tinha, como já afirmamos, o propósito de cumprir a $4^{\text {a }}$ fase on line da ONHB. A princípio, tanto o nosso empenho, enquanto professores orientadores, quanto o dos estudantes, era chegarmos à etapa final, presencial, na Unicamp. Entretanto, o desenvolvimento da tarefa pelas equipes, sob o nosso acompanhamento em todos os passos (desde as escolhas dos lugares visitados pelos alunos e dos sujeitos que eles entrevistariam até o relatório final), revelou-nos muito mais que uma simples competição para ganhar uma medalha: era um momento de aprendizagem de uma história que não está presente nos livros didáticos, mas sim no cotidiano da cidade, em suas ruas, praças e subúrbios. Dessa perspectiva, conforme Medeiros Neta (2010), a cidade não é cenário inerte, mas uma materialidade instrutiva, corpo e campo gestor de educabilidades. Para essa pesquisadora, "aprender a cidade é entender a cidade como conteúdo educativo, pois o conhecimento informal que gera o meio urbano é, por sua vez, conhecimento sobre esse próprio meio. A cidade que ensina a si mesma” (2010, p.218-219, grifos da autora).

Em outras palavras, a tarefa proposta pela ONHB envolveu um conjunto de atividades (entrevistas, observação participante, registros escritos, orais e visuais) que superaram as discussões meramente conteudistas que, não raro, 
ocorrem no cotidiano das aulas de História e de outras disciplinas. Pudemos confirmar a análise feita por Minayo sobre o trabalho de campo (2007, p.61): ele "permite a aproximação do pesquisador da realidade sobre a qual formulou uma pergunta, mas também estabelecer uma interação entre os 'atores' que conformam a realidade e, assim, constrói um conhecimento importantíssimo para quem faz pesquisa social".

A tarefa desenvolvida tornou evidente o fato de que a escola não é apenas o lugar onde os alunos obtêm informações de maneira sistematizada pelas disciplinas escolares, "mas também a instituição em que se aprendem conteúdos sociais e culturais associados a comportamentos, valores e ideários políticos" (Bittencourt, 2011, p.106). Isso pode ser percebido nas avaliações feitas pelos alunos:

A tarefa nos possibilitou conhecer um mundo antigo e desconhecido aos nossos olhos, pois a maioria dos jovens mossoroenses sequer andou de trem.

A entrevista nos propiciou um momento único, do qual a experiência de vida do Sr. [ferroviário], um homem simples, nos encheu de muito orgulho e sabedoria.

Os relatos da $\mathrm{Sr}^{\mathrm{a}}$ [bordadeira] emocionaram a equipe, ao passo que evidenciaram as mudanças geradas pelo tempo em sua profissão.

À medida que a entrevista é conduzida, a equipe pode fazer uma viagem ao passado, compartilhando com o Sr. [alfaiate]. Alguns passam, olham e menosprezam, outros passam, olham e imaginam o que terá existido ali [ na antiga alfaiataria] tempos atrás, e isso é sentir a história. Estudar a história é fascinante, vai além da tarefa objetiva de ler livros e revistas e exige reflexão. É preciso pensar os sujeitos históricos que ali existiam, como eram as condições de vida e trabalho daquela época e como aquele local influenciou para materializar a história das pessoas que lá trabalharam. Portanto, conversar e discutir com as pessoas que viveram e trabalharam naquela época é essencial, uma vez que o entrevistado é a história viva, e a partir de suas memórias é possível conhecer e refletir sobre aquela época.

Durante sua explanação, o Sr. [plaqueiro] fez a equipe perceber o quanto o artesanato envolve sentimentos. Essa arte, existente desde os primórdios da humanidade, exige do profissional não apenas habilidade, mas, acima de tudo, amor ao que se faz ... No atual cenário capitalista, toda essa irreverente maneira de trabalhar encanta e surpreende as pessoas. Encanta, por toda a dedicação ao trabalho 
manual de seus funcionários, e surpreende, por preservar e promover os patrimônios industriais da cidade. São em lugares como este que é visto um verdadeiro show de habilidades: corpo e mente trabalhando juntos e dando resultados.

As observações proferidas pelas equipes nos revelam a implicação cultural, social e política dessa atividade para a formação humanística de estudantes de cursos técnicos, que, ao longo da história, no Brasil, têm sido vistos apenas como formadores e qualificadores de mão de obra para o mercado de trabalho. Nessa direção, ao refletirem sobre a trajetória da Educação Profissional no Brasil, Nóbrega e Souza (2015, p.270) destacam a função que a escola passou a assumir, sobretudo a partir de meados do século XX, como transformadora da realidade nacional: "a educação faria do homem um cidadão necessário à vida econômica do país, a partir do ensino técnico-profissional capaz de formar mão de obra nacional especializada em um país que objetivava o progresso e a modernidade por intermédio do desenvolvimento industrial".

Com base no exposto pelas equipes, o trabalho de campo proposto pela $3^{\text {a }}$ ONHB colaborou para que os discentes percebessem as continuidades e descontinuidades dos fatos históricos e assimilassem as relações entre passado, presente e futuro, necessárias para a compreensão dos problemas e das mudanças no mundo contemporâneo. Para além de uma formação puramente tecnicista, a tarefa foi desencadeadora de conhecimentos acerca das transformações tecnológicas e de suas influências nas vidas dos trabalhadores. Dessa forma, foi ao encontro das prescrições da "Proposta de trabalho da disciplina de História nos Cursos Técnicos de Nível Médio” (PTDEM), que adota o eixo temático "O trabalho e a Indústria no Brasil". Conforme o documento, “A justificativa central dessa opção era a de que esse eixo temático possibilitaria fazer a análise do processo histórico nacional brasileiro, ao mesmo tempo que remeteria ao estudo dos conceitos de trabalho, indústria, técnica, tecnologia e cidadania” (Instituto..., 2012. p.9).

Em outros termos, a tarefa da ONHB proporcionou uma articulação entre trabalho, ciência e cultura no Ensino Médio, sob uma perspectiva de formação humana, como defendem os estudiosos da Educação Profissional. Para eles, na sociedade capitalista dependente da economia internacional em que estamos inseridos, é necessário oferecer aos estudantes de Ensino Médio, em sua 
maioria jovens, uma educação que vá além do operacional, dos conhecimentos funcionais, pois, como afirma Frigotto (2004, p.57), esses discentes não são

sujeitos sem rosto, sem história, sem origem de classe ou fração de classe. Os sujeitos a que nos referimos são predominantemente jovens e, em menor número, adultos, de classe popular, filhos de trabalhadores assalariados ou que produzem a vida de forma precária ou por conta própria, do campo e da cidade, de regiões diversas e com particularidades socioculturais e étnicas.

Ramos (2004) endossa a finalidade do Ensino Médio e reforça o seu caráter político de emancipação e aprimoramento da pessoa humana. Para ela, sujeitos e conhecimentos são elementos que dão sentido ao Ensino Médio. O público que estuda nesse nível é composto por

sujeitos que têm uma vida, uma história e uma cultura. Que têm necessidades diferenciadas, mas conquistaram direitos universais. Conhecimentos que são construídos socialmente ao longo da história, constituindo o patrimônio da humanidade, a cujo acesso, portanto, todos têm direito. É preciso, então, construir um projeto de ensino médio que supere a dualidade entre formação específica e formação geral e que desloque o foco de seus objetivos do mercado de trabalho para a pessoa humana. (Ramos, 2004, p.39-40)

Para as equipes envolvidas na $4^{\text {a }}$ fase da $3^{\text {a }} \mathrm{ONHB}$, o tema abordado pela pesquisa de campo foi de grande relevo para que compreendessem a extinção ou o declínio, ou mesmo a emergência e o auge de uma profissão. Importa que os estudantes tenham percebido esse processo, não como algo natural, mas como parte de um contexto histórico que, na atualidade, tem relação direta com as mudanças impostas pelo desenvolvimento tecnológico a serviço da acumulação do capital, estabelecendo, assim, uma nova cultura do trabalho. Segundo Antunes (2003), há um caráter contraditório nessas mudanças, pois, se, por um lado, há um processo de qualificação do trabalho a partir de sua maior intelectualização, de outro, há um processo inverso de desqualificação e precarização do trabalho. Todavia, para ele,

a heterogeneização, complexificação e fragmentação da "classe que vive do trabalho" não caminha no sentido de sua extinção; ao contrário, pode significar o delineamento de um processo de emancipação dos trabalhadores enquanto classe, 
desde que persigam o desafio de que, respeitando as diferenças e divergências entre os segmentos dos trabalhadores, possam se aglutinar enquanto classe e não enquanto corporações. (Antunes, 2003, p.50)

Outro aspecto que merece ser ressaltado na atividade proposta pela $3^{\mathrm{a}}$ ONHB diz respeito à importância dada, pelos organizadores do evento, à concepção de fonte histórica, vista de forma ampla. Em todas as fases, os estudantes discutem a história a partir de documentos escritos (obras literárias e textos oficiais) e visuais (fotografias e pinturas) e, na tarefa que aqui relatamos, fica evidente a valorização dada à história oral e ao patrimônio histórico material de uma cidade como fontes para a reconstrução da memória do trabalho.

Apesar de não ser objeto deste artigo abrir discussões teóricas no campo da historiografia, é importante destacar que não há um consenso entre os pesquisadores sobre o significado da história oral. Para alguns, ela é uma técnica em que interessam as experiências com gravações, transcrições e conservação de entrevistas e o aparato que as cerca: tipos de aparelhagem de som, formas de transcrições de fitas, modelos de organização de acervo etc. Outros postulam para a história oral um status de disciplina que inaugurou técnicas específicas de pesquisa, procedimentos metodológicos singulares e um conjunto próprio de conceitos (Amado; Ferreira, 2006).

Para além da pesquisa acadêmica, a história oral também pode ser utilizada como um procedimento didático nas aulas de História. Para Santiago e Magalhães (2015, p.32), “o uso da história oral pode ser feito por educadores preocupados em fazer com que a história da comunidade, sua memória, suas lembranças, estejam conectadas de forma mais ampla ao cotidiano da escola e às atividades escolares". Num processo interativo, visto que o estudante participa diretamente da construção do conhecimento por meio das entrevistas realizadas, as histórias narradas passam a ter papel importante no aprendizado, pois permitem que um indivíduo se conheça e reconheça o outro.

Ao pôr em prática a tarefa proposta pela $4^{\mathrm{a}}$ fase da $3^{\mathrm{a}} \mathrm{ONHB}$, as entrevistas e as visitas aos lugares de memória do trabalho proporcionaram aos estudantes algumas habilidades semelhantes às desenvolvidas pelo historiador ao fazer a escrita da história: situar-se como sujeito histórico em um processo em construção, interrogar tempos e espaços, realizar um exercício em história oral com ênfase no aspecto da memória e dos "lugares de memória" (Nora, 1993). 
No entanto, não é demais destacar como a ONHB concebe e se utiliza da história oral como a aplicação de um método específico para se fazer história. Em 2010, por exemplo, a prova final, realizada na Unicamp, solicitou às equipes finalistas uma definição de história oral e questionou se ela seria uma forma mais completa e verdadeira de se fazer história. Posteriormente, a Comissão Organizadora, com base nas respostas dadas, comentou:

Observamos que muitos erroneamente descreveram a tradição, ou a tradição oral (uma geração transmitindo oralmente seus conhecimentos à outra geração dentro de uma comunidade fechada), e não a história oral, que é a aplicação de um método específico para se fazer história. Ainda, a mesma questão oferecia uma definição simplista e errônea de história oral, e esperava-se que os estudantes observassem que a história oral não é uma forma mais completa e verdadeira de se fazer história. Ao longo dos comentários às questões da Olimpíada, salientamos que essa forma de produzir conhecimento histórico possui perigos e limites, sendo que ela ensina mais sobre como as pessoas lembram do que sobre o passado em $\mathrm{si}^{4}$

As entrevistas que as equipes realizam como tarefa da ONHB também vão ao encontro do ensino de História, considerando a categoria consciência histórica. ${ }^{5}$ Assim, a tarefa possibilitou "desenvolver atividades que permitam que o educando conheça história - de preferência a história que, de forma mais aproximada, seja sua história - ao mesmo tempo que conhece diferentes formas pelas quais se lhe atribuiu significado" (Cerri, 2011, p.130). Possibilitou também a compreensão de que a história não está presente apenas no que foi considerado como grandes fatos e nem nos feitos dos "homens ilustres", mas que se constrói a partir do coletivo das vidas de todos os indivíduos, como a do próprio discente, mesmo em momentos mais simples do cotidiano.

Por fim, nossa avaliação positiva quanto à tarefa proposta pela $\mathrm{ONBH}$ não diz respeito apenas às várias medalhas de ouro, prata, bronze e menções honrosas que temos auferido com nosso desempenho durante as várias edições da Olimpíada, mas também ao trabalho em grupo desenvolvido com colegas professores e equipes de alunos. Somado a isso, há um enorme ganho em termos de formação continuada dos docentes envolvidos e crescimento pessoal dos estudantes (a interação com os colegas, as autoavaliações, a superação de conflitos que ocorrem entre os membros das equipes e entre elas). 
Do ponto de vista do processo de ensino-aprendizagem, nossa avaliação é igualmente positiva, visto que esses alunos passam a adquirir conhecimentos que transcendem os livros didáticos e aprendem história por meio não convencionais, como é o caso das pesquisas de campo, das leituras de documentos comumente usados pelos historiadores, do uso de imagens, dentre tantos outros meios que permitem uma aprendizagem para além da "mesmice" a que estão acostumados.

Enfim, no caso específico da Educação Profissional, consideramos que a ONHB colabora para a formação de estudantes-cidadãos-trabalhadores e estimulam a práxis pedagógica dos educadores ao desenvolver metodologias que enfatizam a construção de estratégias, a criatividade, a iniciativa pessoal, o trabalho coletivo e a autonomia advinda da confiança na capacidade de enfrentar desafios. Lembremos que, dentre os eixos norteadores do Ensino Médio Integrado, apresentados por Moura (2007, p.23), está a pesquisa como princípio educativo. Para ele:

A pesquisa deve instigar o estudante no sentido da curiosidade em direção ao mundo que o cerca, gerar inquietude, para que ele não incorpore "pacotes fechados" de visão de mundo, de informações e de saberes, quer sejam do senso comum (saber cotidiano), escolares ou científicos. Esse tipo de atitude, quando despertada nas primeiras fases escolares, contribui para que, nas faixas etárias e níveis educacionais mais avançados, o estudante possa formular questões de investigação no campo mais formal, quer seja na sua forma aplicada ou na denominada pesquisa de base ou acadêmica.

Infelizmente, apesar da relevância da ONHB para o processo de ensino-aprendizagem e para o estímulo à pesquisa em história, por ser uma olimpíada do conhecimento, ela também gera competição ${ }^{6}$ entre equipes, mesmo que seja constantemente evitada pelos promotores do evento e por nós, professores envolvidos. No nosso caso, temos alcançado êxito nesse aspecto.

\section{REFERENCIAS}

AMADO, Janaína; FERREIRA, Marieta de M. Apresentação. In: (Org.) Usos e abusos da história oral. 8.ed. Rio de Janeiro: Ed. FGV, 2006. p.vii-xxv.

ANTUNES, Ricardo. Adeus ao trabalho? Ensaio sobre as metamorfoses e a centralidade do mundo do trabalho. Campinas: Cortez, 2003. 
BITTENCOURT, Circe. Ensino de história: fundamentos e métodos. 4.ed. São Paulo: Cortez, 2011.

CERRI, Luís F. Ensino de história e consciência histórica. Rio de Janeiro: Ed. FGV, 2011.

DEPARTAMENTO DE HISTÓRIA DA UNIVERSIDADE ESTADUAL DE CAMPINAS (UNICAMP). Regulamento da $8^{a}$ Olimpíada Nacional em História do Brasil. Campinas, SP: Unicamp, 2016. Disponível em: http://www.olimpiadadehistoria. com.br/8-olimpiada/regulamento/index; Acesso em: 27 jun. 2016.

FIRER, Marcelo. Cerimônia de lançamento da $4^{a}$ ONHB. Brasília, 20 ago. 2012. Disponível em: http://www.youtube.com/embed/ElJFh4kHv4g; Acesso em: 20 fev. 2016.

FRIGOTTO, Gaudêncio. Sujeitos e conhecimentos: os sentidos do ensino médio. In: FRIGOTTO, Gaudêncio; CIAVATTA, Maria (Org.) Ensino Médio: ciência, cultura e trabalho. Brasília:, MEC/Semtec, 2004. p.53-70.

INSTITUTO FEDERAL DE EDUCAÇÃO, CIÊNCIA E TECNOLOGIA DO RIO GRANDE DO NORTE (IFRN). Proposta de trabalho da disciplina de História nos Cursos Técnicos de Nível Médio. Natal, 2012.

MEDEIROS NETA, Olívia de M. É possível uma pedagogia da cidade? Revista HISTEDBR on line, Campinas, n.40, p.212-221, dez. 2010. Disponível em: http://www. histedbr.fe.unicamp.br/revista/edicoes/40/art13_40.pdf; Acesso em: 18 set. 2016.

MELLO, Kênia A. de. Pensamento Complexo: uma nova e desafiadora forma de pensar a educação com base nas ideias de Edgar Morin. In: LIBÂNEO, José C.; SUANNO, Marilza V. R.; LIMONTA, Sandra V. (Org.) Concepções e práticas de ensino num mundo em mudança: diferentes olhares para a didática. Goiânia: Ceped; Ed. PUC-Goiás, 2011. p.101-121.

MENEGUELLO, Cristina. Olimpíada Nacional em História do Brasil: uma aventura intelectual? História Hoje, v.5, n.14, p.1-14, 2011. Disponível em: http://www. anpuh.org/revistahistoria/view?ID_REVISTA_HISTORIA=14; Acesso em: 17 set. 2016.

MINAYO, Maria C. de S. Trabalho de campo: contexto de observação, interação e descoberta. In: . (Org.) Pesquisa social: teoria, método e criatividade. 25.ed. Petrópolis: Vozes, 2007. p.61-77.

MOURA, Dante H. Educação básica e educação profissional e tecnológica: dualidade histórica e perspectiva de integração. Holos, Natal, v.2, p.1-27, 2007. Disponível em: http://www2.ifrn.edu.br/ojs/index.php/HOLOS/article/viewFile/11/110; Acesso em: 18 set. 2016.

NÓBREGA, Erickson F. da; SOUZA, Francisco das C. S. Educação Profissional no Brasil: uma trajetória de dualidade e exclusão. Revista Ensino Interdisciplinar, v.1, n.3, p.266-276, dez. 2015. Disponível em: http://periodicos.uern.br/index.php/ RECEI/article/viewFile/1698/918; Acesso em: 17 set. 2016. 
NORA, Pierre. Entre memória e história: a problemática dos lugares. Trad. Yara A. Khoury. Projeto História, São Paulo: Educ, n.10, p.7-28, dez. 1993. Disponível em: http://revistas.pucsp.br/index.php/revph/article/viewFile/12101/8763; Acesso em: 17 set. 2016.

RAMOS, Marise N. O projeto unitário de ensino médio sob os princípios do trabalho, da ciência e da cultura. In: FRIGOTTO, Gaudêncio; CIAVATTA, Maria (Org.) Ensino Médio: ciência, cultura e trabalho. Brasília, MEC/Semtec, 2004. p.37-52.

REZENDE, Flávia; OSTERMANN, Fernanda. Olimpíadas de ciências: uma prática em questão. Ciência \& Educação, Bauru, v.18, n.1, p.245-256, 2012. Disponível em: http://www.scielo.br/pdf/ciedu/v18n1/15.pdf; Acesso em: 17 set. 2016.

RODRIGO, Ênio. Olimpíadas científicas, jogos sem perdedores, 2013. Disponível em: https://eniorodrigo.wordpress.com/2013/02/25/olimpiadas-cientificas-jogos-sem-perdedores/; Acesso em: 8 abr. 2016.

RÜSEN, Jörn. Razão histórica. Trad. Estevão de Rezende Martins. Brasília: Ed. UnB, 2001.

SANTHIAGO, Ricardo; MAGALHÃES, Valéria B. de. História oral na sala de aula. Belo Horizonte: Autêntica, 2015.

\section{NOTAS}

${ }^{1}$ Disponível em: https://www.olimpiadadehistoria.com.br/8-olimpiada/inicio/index; Acesso em: 4 jul. 2016.

${ }^{2}$ Para a última fase dessa edição da ONHB, realizada na Unicamp, foi indicada às equipes finalistas a leitura do segundo capítulo da obra "Sobrados e Mucambos", de Gilberto Freyre, cuja discussão salienta as transformações dos ofícios no Brasil, na passagem do mundo rural-agrário para o urbano-industrial.

${ }^{3}$ Usando critérios de qualidade e densidade dos jornais produzidos por essas equipes, para a elaboração deste artigo, selecionamos cinco dentre as sete que realizaram esses trabalhos.

${ }^{4}$ Esse documento infelizmente não se encontra mais disponível no sítio da ONHB. Porém, temo-lo guardado em nossos arquivos pessoais.

${ }^{5}$ Há ainda muita discussão acerca do que seja consciência histórica. Nos limites deste artigo, não temos condições de aprofundar tal debate. Sugerimos, assim, a leitura de Rüsen (2001) e Cerri (2011).

${ }^{6}$ A competitividade nas chamadas olimpíadas do conhecimento é um tema que merece maior discussão. Não o fizemos aqui por temermos um desvio do objetivo deste artigo. Para os interessados no tema, sugerimos a leitura do trabalho de Rezende e Ostermann (2012).

Artigo recebido em 15 de julho de 2016. Aprovado em 19 de setembro de 2016. 